\title{
An awake double lumen endotracheal tube intubation using the Clarus Video System in a patient with an epiglottic cyst
} -a case report-

\author{
Hyungseok Seo, Gunn Lee, Seung-il Ha, and Jun-Gol Song \\ Department of Anesthesiology and Pain Medicine, Asan Medical Center, University of Ulsan College of Medicine, Seoul, Korea
}

\begin{abstract}
A 54-year-old male patient was scheduled for an elective pylorus-preserving pancreaticoduodenectomy combined with video-assisted thoracic surgery at our hospital. This patient had a history of intubation failure in other institutions due to an epiglottic cyst. An airway assessment of the patient was normal. A preoperative laryngoscopy revealed a bulging epiglottic mass covering most of the epiglottis and occupying most of the pharyngeal space. The patient was administered intravenous midazolam $1 \mathrm{mg}$, fentanyl $50 \mu \mathrm{g}$, and glycopyrrolate $0.2 \mathrm{mg}$. A bilateral superior laryngeal nerve block was then performed with $2 \%$ lidocaine $2 \mathrm{ml}$ on each side. A $10 \%$ lidocaine spray was applied on to the oropharynx. After preoxygenation with $100 \%$ oxygen over 10 minutes, a rigid fiberscope with an optical stylet loaded with a 37 Fr double lumen endotracheal tube was inserted orally and passed into the glottic aperture. The patient was fully awakened after surgical procedure and was transferred to the recovery room after extubation. (Korean J Anesthesiol 2014; 66: 157-159)
\end{abstract}

Key Words: Airway obstruction, Difficult intubation, Laryngeal mass.

Epiglottic cysts can cause difficulties with airway management during general anesthesia, even when the patient is asymptomatic [1]. Large-sized epiglottic cysts can disrupt optimal ventilation, leading to serious consequences such as hypoxia [1]. Many airway management techniques such as awake intubation can be applied in these cases. The Clarus Video System (CVS; Clarus Medical, Minneapolis, MN, USA), a rigid fiberscope with an intubating stylet has been used for difficult intubation cases $[2,3]$. Herein, we report our experience with a successful awake double lumen endotracheal tube (DLT; Silbroncho, Fuji Systems
Corporation, Tokyo, Japan) intubation using CVS in a patient with a large epiglottic cyst who required isolation of the lungs for a combined pylorus-preserving pancreaticoduodenectomy (PPPD) and thoracic surgery.

\section{Case Report}

A 54-year-old male, $165.8 \mathrm{~cm}$ in height, weighing $55.6 \mathrm{~kg}$ was scheduled for PPPD and video-assisted thoracic surgery (VATS) due to a previously diagnosed duodenal cancer and a $1.1 \mathrm{~cm}$ -

Received: November 5, 2012. Revised: 1st, December 14, 2012; 2nd, January 2, 2013; 3rd, January 9, 2013. Accepted: January 15, 2013.

Corresponding author: Jun-Gol Song, M.D., Department of Anesthesiology and Pain Medicine, Asan Medical Center, University of Ulsan College of Medicine, 388-1, Pungnap 2-dong, Songpa-gu, Seoul 138-736, Korea. Tel: 82-2-3010-3869, Fax: 82-2-3010-6790, E-mail: jungol.song@amc.seoul.kr (c) This is an open-access article distributed under the terms of the Creative Commons Attribution Non-Commercial License (http:// creativecommons.org/licenses/by-nc/3.0/), which permits unrestricted non-commercial use, distribution, and reproduction in any medium, provided the original work is properly cited. 
sized mass on the right apex of the lung, suspected to be a duodenal cancer metastasis. He had no other underlying disease but had a known large epiglottic cyst, which resulted in intubation failure and the cessation of surgery at a previous hospital. Laryngoscopic examination revealed a bulge arising from the center of the epiglottis and stretching to the glottis. It covered most of the epiglottis and occupied most of the pharyngeal space (Fig. 1). Despite the large size $(>2 \mathrm{~cm})$ of this epiglottic cyst, the patient did not complain of any laryngeal symptoms such as dyspnea, dysphagia, hoarseness, and sleep apnea. A preoperative evaluation by an otolaryngologist concluded that the patient be kept under close observation as he did not show any symptoms. Preoperative airway assessment demonstrated excellent mouth opening and that the jaw could be thrust forward, corresponding to a class 1 Mallampati score. His temporomandibular joint

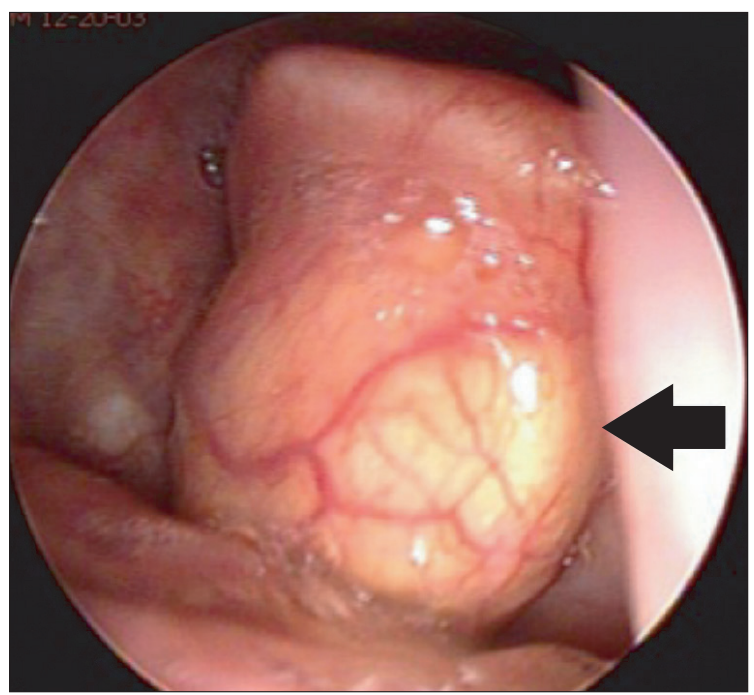

Fig. 1. Fiberscopic view during an otolaryngologic examination. A large cystic mass (arrow) arising from the anterior epiglottis could be observed.

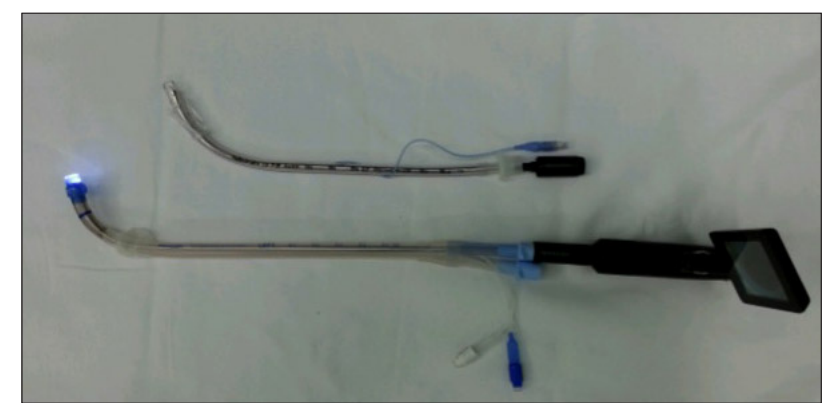

Fig. 2. The Clarus Video System with different types of stylets. Stylets are interchangeable in accordance with the length of the endotracheal tube. The longer type (lower) loaded with a double lumen endotracheal tube was used in the present case. activity, neck movement and thyromental distance were also normal.

The patient was informed at the preoperative visit about the likelihood of a difficult intubation, the procedures involved with an awake intubation, and the necessity for his cooperation with this procedure. In the operation room, we decided to perform an awake orotracheal intubation using CVS loaded with a left $37 \mathrm{Fr}$ DLT (Fig. 2). The patient was premedicated intravenously with $0.2 \mathrm{mg}$ glycopyrrolate, and $50 \mu \mathrm{g}$ fentanyl. A superior laryngeal nerve block with $2 \mathrm{ml}$ of $2 \%$ lidocaine was performed bilaterally and $10 \%$ lidocaine spray was applied to the oropharyngeal mucosal surface with direct laryngoscopic exploration. Preoxygenation was performed using a closed facemask with $100 \%$ oxygen delivery at $8 \mathrm{~L} / \mathrm{min}$ over 10 minutes. The CVS loaded with a lubricated 37 Fr DLT was smoothly inserted into the posterior pharynx. After identifying the epiglottis and glottis opening, the distal tip of the CVS was carefully advanced below the mass to the glottis aperture (Fig. 3). The DLT was further advanced until the tracheal cuff passed through the vocal cord. After endotracheal intubation was confirmed by auscultation of the bilateral breath sound and end-tidal $\mathrm{CO}_{2}$ detection, the patient was given propofol $140 \mathrm{mg}$ and vecuronium bromide $10 \mathrm{mg}$ intravenously.

The time taken to complete awake intubation was less than 1 minute. Spontaneous breathing was maintained and no desaturation occurred during the entire procedure. General anesthesia was maintained with a $2-3$ vol $\%$ of sevoflurane with $50 \%$ oxygen and medical air mixture. After the position change for VATS, the final position of the DLT was confirmed by flexible fiberoptic bronchoscopy (FOB) (Olympus LF-DP; Olympus optical Inc., Tokyo, Japan). At the completion of VATS, the patient's position

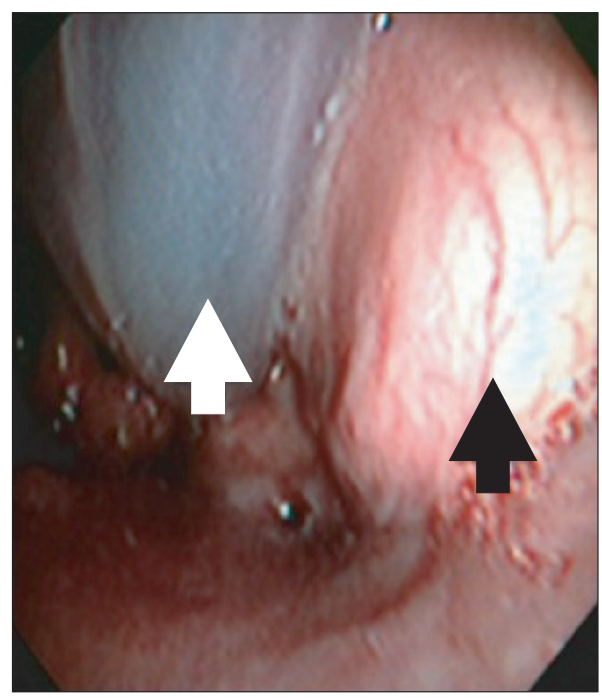

Fig. 3. Fiberoptic bronchoscopic view following a successful awake intubation. A double lumen endotracheal tube (white arrow) was inserted beside the epiglottic (black arrow) cyst without trauma. 
was changed to supine and the PPPD preceded without an endotracheal tube change. Although the DLT is a larger tube with the potential to cause more airway trauma or edema postoperatively, we decided not to change the tube because this would have caused an even higher risk to the patient from possible cyst damage or intubation failure.

After these surgical procedures were completed, the patient was fully awakened and extubated. The patient was then transferred to the general ward via a recovery room with no respiratory or hemodynamic complications.

\section{Discussion}

Epiglottic cysts, even in asymptomatic patients, can lead to unanticipated difficulties in ventilation, intubation or both after the induction of anesthesia and can be potentially life threatening in such situations. In addition, muscle relaxation can aggravate airway obstruction in such cases and special preoperative airway management strategies need to be adopted. Previous reports have described the use of a laryngeal mask airway or small-sized endotracheal tube in cases of vallecular cysts $[4,5]$. However, there is a risk in these patients of 'cannot ventilate, cannot intubate' and complications associated with failed intubation such as cyst rupture that could result in unclear visual field and aspiration. In our present case, a lung isolation technique was required to perform VATS. The DLT that we used in this procedure does carry more risk of bleeding and cyst rupture than single-lumen endotracheal tube because of its size and shape. Therefore, we decided to perform an awake intubation using CVS to secure the airway and to directly visualize the cyst without causing damage during DLT intubation.

Although FOB has been advocated as a gold standard for awake intubation, it has a number of disadvantages including the difficulty of the technique, and the availability and cost of the equipment [6]. Moreover, anatomical structures such as the arytenoid cartilage and the resistance of upper airway soft tissue can make it difficult to intubate using FOB. Previous reports have shown that several alternatives to FOB such as lightwand, GlideScope, and the Airway Scope can be effectively used in patients with difficult airways [6-9].

In the present case we used CVS, which is video-guided intubating stylet, instead of FOB. CVS has the advantage of enabling direct observation during intubation thus avoiding blind manipulation and therefore minimizing any trauma to the airway $[10,11]$. The short, rigid but malleable stylet of the CVS can easily overcome the resistance of pharyngeal soft tissue and can be handled conveniently during the procedure [11]. Furthermore, its light source at the tip allows it to be used as a lightwand if blood or secretions obscure the bronchoscopic view. For these reasons, we chose CVS to perform an awake intubation in the present case instead of a conventional FOB assisted technique.

In conclusion, awake intubation with CVS is a useful modality in cases with an anticipated difficult airway due to an epiglottic cyst and is a good alternative to FOB assisted awake intubation. It must be noted also that because the patient's cooperation is indispensable when performing an awake intubation, sufficient preoperative information regarding the intubation and anesthesia procedures needs to be provided to the patient.

\section{References}

1. Sonny A, Nagaraj G, Ramachandran R. Asymptomatic epiglottic cyst: a rare cause of unanticipated difficult intubation. Middle East J Anesthesiol 2011; 21: 119-20.

2. Cheng WC, Lan CH, Lai HY. The Clarus Video System (Trachway) intubating stylet for awake intubation. Anaesthesia 2011; 66: 1178-80.

3. Costa F, Mattei A, Massimiliano C, Cataldo R, Agrò FE. The Clarus Video System as a useful diagnostic tool. Anaesthesia 2011; 66: 135-6.

4. Rivo J, Matot I. Asymptomatic vallecular cyst: airway management considerations. J Clin Anesth 2001; 13: 383-6.

5. Kariya N, Nishi S, Minami W, Funao T, Mori M, Nishikawa K, et al. Airway problems related to laryngeal mask airway use associated with an undiagnosed epiglottic cyst. Anaesth Intensive Care 2004; 32: 268-70.

6. Lin N, Li M, Shi S, Li TZ, Zhang BX. Shikani ${ }^{\mathrm{TM}}$ Seeing Optical Stylet-aided tracheal intubation in patients with a large epiglottic cyst. Chin Med J (Engl) 2011; 124: 2795-8.

7. Behringer EC, Kristensen MS. Evidence for benefit vs novelty in new intubation equipment. Anaesthesia 2011; 66 Suppl 2: 57-64.

8. Choi GS, Park SI, Lee EH, Yoon SH. Awake Glidescope ${ }^{\circledR}$ intubation in a patient with a huge and fixed supraglottic mass -A case report. Korean J Anesthesiol 2010; 59 Suppl: S26-9.

9. Saha AK, Higgins M, Walker G, Badr A, Berman L. Comparison of awake endotracheal intubation in patients with cervical spine disease: the lighted intubating stylet versus the fiberoptic bronchoscope. Anesth Analg 1998; 87: 477-9.

10. Halligan M, Charters P. A clinical evaluation of the Bonfils Intubation Fibrescope. Anaesthesia 2003; 58: 1087-91.

11. Hung KC, Tan PH, Lin VC, Wang HK, Chen HS. A comparison of the Trachway intubating stylet and the Macintosh laryngoscope in tracheal intubation: a manikin study. J Anesth 2013; 27: 205-10. 